\title{
AGROMETEOROLOGIA
}

\section{FENOLOGIA E ESTIMATIVA DA DURAÇÃO DO CICLO DA ZÍNIA ‘PROFUSION CHERRY' CULTIVADA EM VASOS EM AMBIENTE PROTEGIDO ( ${ }^{\mathbf{1}}$ )}

\author{
CHARLESTON GONÇALVES $\left({ }^{2 *}\right)$; MÁRIO JOSÉ PEDRO JÚNIOR $\left({ }^{3,4}\right)$; \\ CARLOS EDUARDO FERREIRA DE CASTRO $\left({ }^{3}\right)$
}

\begin{abstract}
RESUMO
Durante o período de 4/2/05 a 17/6/05, estudou-se a fenologia da zínia 'Profusion Cherry', envasada e cultivada em ambiente protegido, em diferentes datas de semeadura. A duração do ciclo da planta foi influenciada pela temperatura do ar e pelo fotoperíodo. A média de duração do subperíodo semeaduraprimeira flor aberta variou de 39 dias, para as semeaduras de 11/3/05 e 18/3/05, a 63 dias, para a semeadura de 10/6/05. Além disso, constatou-se que a estimativa da duração do subperíodo (D) semeadura-primeira flor aberta pode ser obtida pela equação: $1 / D=0,019108+0,001968 T-0,00352 \mathrm{~F}\left(\mathrm{R}^{2}=0,99\right)$, onde T é a temperatura média $\left({ }^{\circ} \mathrm{C}\right)$ e $\mathrm{F}$ é o fotoperíodo médio (horas).
\end{abstract}

Palavras-chave: Zinnia, ciclo, temperatura, fotoperíodo.

\section{ABSTRACT \\ PHENOLOGY AND CYCLE LENGTH ESTIMATES FOR POTTED ZINNIA “PROFUSION CHERRY" GROWN UNDER PLASTIC COVER}

Phenology of potted Zinnia 'Profusion Cherry' grown in a greenhouse with plastic cover was evaluated for weekly sowing dates from: $2 / 4 / 05$ to $6 / 17 / 05$. The length of plant cycle was influenced by air temperature and photoperiod. The average length of the phase sowing to first open flower varied from 39 days for the sowing dates of 03/11/05 and 03/18/05 to 63 days for 06/10/05. It was also showed that estimates of the length (D) of the period sowing to first open flower could be obtained by the following equation: $1 / \mathrm{D}=0.019108+0.001968 \mathrm{~T}-0.00352 \mathrm{~F}\left(\mathrm{R}^{2}=0.99\right)$ where, $\mathrm{T}$ is the mean air temperature $\left({ }^{\circ} \mathrm{C}\right)$ and $\mathrm{F}$ is the mean photoperiod (hours).

Key words: cycle, temperature, photoperiod.

$\left({ }^{1}\right)$ Recebido para publicação em 26 de setembro de 2006 e aceito em 12 de setembro de 2007.

$\left({ }^{2}\right)$ Unidade de Pesquisa e Desenvolvimento de Ubatuba /APTA, Caixa Postal 59, 11680-000 Ubatuba (SP). E-mail: charleston@apta.sp.gov.br $\left(^{*}\right)$ Autor correspondente.

$\left({ }^{3}\right)$ Instituto Agronômico (IAC/APTA/SAA), Caixa Postal 28, 13012-970 Campinas (SP).

$\left({ }^{4}\right)$ Bolsista do CNPq. 


\section{INTRODUÇÃO}

No Brasil, observa-se no mercado consumidor de flores grande interesse pela introdução de novas espécies e cultivares, com crescente demanda por flores envasadas. Há alguns anos, o mercado interno temse tornado mais exigente quanto à qualidade $\mathrm{e}$ apresentação dos produtos. Atualmente, a floricultura está altamente profissionalizada e para um produtor ser competitivo, os requisitos mínimos, além de conhecimento do produto a ser comercializado, baseiam-se na obtenção, durante o processo produtivo, de elevados índices de produtividade, de padronização e de boa apresentação e qualidade.

A zínia (Zinnia elegans Jacq.) é uma planta herbácea, anual, de pleno sol, pertencente à família Compositae, considerada como planta nativa das Américas (Sacalis, 1993), originária do México, com caule piloso e folhas simples (TORRES, 1963). É uma ornamental cultivada para a produção de flores de corte devido à sua longa durabilidade, tanto para regiões de temperatura amena como para áreas tropicais.

O híbrido Profusion Cherry é de excelente desempenho na produção de flores em vaso, possui porte baixo, ereto e compacto, e bom preenchimento de vaso na parte aérea. Demanda o uso de técnicas de cultivo simples, proporcionando baixo custo de produção, tornando-se um produto cada vez mais acessível ao produtor e ao consumidor. Por essas características tem grande potencial para o mercado de flores envasadas, por aliar seu curto ciclo de produção à qualidade do produto e atender à crescente exigência do mercado consumidor.

O conhecimento da duração do ciclo das flores ornamentais é de grande importância para o produtor, permitindo o planejamento do fluxo de entrega de vasos para o mercado consumidor.

No Brasil, PINTO (1996), trabalhando com Zinnia elegans, avaliou em três épocas de semeadura (dezembro, fevereiro e abril), a duração de diferentes subperíodos fenológicos, verificando terem sido influenciados pela época de semeadura. O número de dias necessários para atingir a floração foi maior na semeadura de abril (71 dias) e menor em dezembro (53 dias).

A temperatura e o fotoperíodo são os principais fatores que determinam a duração do subperíodo até o início da floração das culturas (GoNZALES et al., 2004). Para cultivos não sensíveis ao fotoperíodo ou que estejam dentro da faixa ótima fotoperiódica, a taxa de desenvolvimento definida como o inverso da duração do subperíodo fenológico é uma função linear da temperatura (YAN e WALLACE, 1998; BERTERO et al., 1999; RoDRIGUEs et al., 2001; GonZALES et al., 2004).
Por outro lado, em culturas sensíveis ao fotoperíodo, a taxa de desenvolvimento até o aparecimento das primeiras flores pode ser estimada por modelos aditivos (BERTERo et al., 1999 e YAN e Wallace, 1998). Para a soja, Rodrigues et al. (2001) analisaram o efeito combinado da temperatura e do fotoperíodo no florescimento, obtendo um modelo linear simples de estimativa da data de floração.

Como a previsão da data de floração para a zínia é de grande importância para o produtor, foi desenvolvido este trabalho com o objetivo de determinar a fenologia da cultura, sob temperaturas e fotoperíodos decrescentes e estabelecer uma equação de estimativa da duração do subperíodo: semeaduraprimeira flor aberta, em função da temperatura e do fotoperíodo.

\section{MATERIAL E MÉTODOS}

Foram utilizadas sementes do híbrido Profusion Cherry do cruzamento de Zinnia elegans Jacq. e Zinnia angustifolia HBK. Os lotes originais de sementes, com $90 \%$ de germinação e $99,9 \%$ de pureza física (dados técnicos da Agroflora - Sakata), foram mantidos hermeticamente fechados em sua embalagem original, no interior de caixa de isopor, conservada em câmara fria à temperatura de $5^{\circ} \mathrm{C}$ até o momento do uso, conforme recomendação de BAss (1980).

$\mathrm{O}$ ensaio foi realizado em área experimental do Pólo Regional de Desenvolvimento Tecnológico dos Agronegócios do Leste Paulista, em Monte Alegre do Sul (SP), situada a $22^{\circ} 43^{\prime}$ de latitude sul e $46^{\circ} 37^{\prime}$ de longitude oeste, altitude de 777 metros, no período de 4 de fevereiro a 20 de setembro de 2005 . O experimento foi instalado em estufa tipo túnel, orientada no sentido leste-oeste, com as seguintes dimensões: $30 \mathrm{~m}$ de comprimento, $8 \mathrm{~m}$ de largura e 5 $\mathrm{m}$ de altura, com coberta plástica de polietileno de baixa densidade com espessura de $100 \mu \mathrm{m}$, fechada lateralmente com sombrite $70 \%$.

Os vasos (número 13) que compuseram as parcelas experimentais foram dispostos em bancada de $1 \mathrm{~m}$ de altura do solo com comprimento e largura de 8 e $1,5 \mathrm{~m}$ respectivamente. A semeadura foi feita diretamente nos vasos, à profundidade de $4 \mathrm{~mm}$, o substrato usado para a produção das plantas foi obtido na Empresa Terra do Paraíso especificado como Multiplant TDP 3010, com pH de 6,13. Foram semeadas duas sementes por vaso e após a emergência foi deixada apenas uma planta por vaso.

A parcela experimental foi composta de 36 vasos em esquema de $6 \times 6$. Foram consideradas para as avaliações as 16 plantas centrais. As datas de 
semeadura utilizadas para avaliação dos subperíodos fenológicos foram: $4 / 2 ; 11 / 2 ; 17 / 2 ; 25$ / 2 ; 4/3; 11/3; 18/3; 24/3; 1. $/ 4 ; 08 / 04 ; 15 / 4 ; 22 / 4$; $29 / 4 ; 6 / 5 ; 13 / 5 ; 20 / 5 ; 27 / 5 ; 3 / 6 ; 10 / 6 ; 17 / 6$, no ano de 2005 .

Para determinação das temperaturas máximas e mínimas diárias foi utilizada a estação meteorológica automática da Davis Instruments Corp., com software Groweatherlink versão 1.0, instalada dentro do ambiente protegido, a 1,5 $\mathrm{m}$ do solo.

As avaliações fenológicas foram feitas duas vezes por semana, tendo sido empregada uma escala de notas para identificação dos diferentes estádios fenológicos da planta. A escala de notas considerou os seguintes estádios fenológicos: 0 - semeadura; 1 emergência; 2 - surgimento do primeiro par de folhas verdadeiras; 3 - surgimento do segundo par de folhas verdadeiras; 4 - gema apical florífera visível (2 $\mathrm{mm})$; 5 - primeira flor aberta; 6 - 50\% das flores abertas; 7 $90 \%$ das flores abertas e 8 - senescência (flores descoloridas e folhas amareladas) (GonçALves, 2006).

Os valores médios da duração do subperíodo semeadura-primeira flor aberta (0 a 5) foram comparados por meio de análise de intervalos de confiança (95\%), segundo VIEIRA(1980).

A estimativa da duração do subperíodo fenológico semeadura-primeira flor aberta foi feita baseando-se no conceito da taxa de desenvolvimento, ou seja, o inverso do tempo entre a semeadura e a abertura da primeira flor. De acordo com RoDRIGUES et al. (2001), pode-se analisar a duração do subperíodo como uma função linear e aditiva da temperatura e do fotoperíodo médios, por meio da equação de regressão múltipla:

$$
1 / D=a+b T+c F
$$

sendo $a, b, c$ os coeficientes empíricos da equação; $T$, temperatura média no subperíodo $\left({ }^{\circ} \mathrm{C}\right) ; \mathrm{F}$, fotoperíodo médio no subperíodo (horas); D, duração (dias) do subperíodo.

Os coeficientes da equação de regressão múltipla foram obtidos analisando a duração do subperíodo semeadura primeira flor aberta ( 0 a 5$)$ para as seguintes datas de semeadura: $4 / 2 ; 11 / 2 ; 25 / 2 ; 4$ / $3 ; 11 / 3 ; 24 / 3 ; 1 .^{\circ} / 4 ; 8 / 4 ; 22 / 04 ; 29 / 04 ; 6 / 5 ; 20 / 5$; $27 / 5 ; 3 / 6 ; 10 / 6$.

A validade da equação de regressão múltipla obtida foi feita pela comparação de valores estimados e observados, em condições experimentais, a partir de dados de um conjunto independente, ou seja nas seguintes datas de semeadura: $17 / 02 / 05 ; 18 / 03 / 05$; 15/04/05; 13/05/05 e 17/06/05. A validade das estimativas obtidas foi feita por meio da comparação entre os dados observados e estimados por meio de análise de regressão linear, para verificar a precisão, e do índice de concordância de Willmott (índice d), apresentado por WiLLMOTT et al. (1985), para verificar a exatidão. $\mathrm{O}$ índice $\mathbf{d}$ de Willmott foi obtido usando a seguinte equação:

$$
\mathrm{d}=1-\left[\Sigma(\mathrm{Pi}-\mathrm{Oi})^{2} / \Sigma(|\mathrm{Pi}-\mathrm{O}|+|\mathrm{Oi}-\mathrm{O}|)^{2}\right]
$$

sendo $\mathrm{Pi}$ o valor previsto (estimado); Oi, o valor observado e $\mathrm{O}$, a média dos valores observados.

\section{RESULTADOS E DISCUSSÃO}

\section{Duração dos subperíodos fenológicos}

Na figura 1, são apresentadas as durações dos diferentes subperíodos fenológicos para zínia 'Profusion Cherry' obtidas em diferentes datas de semeadura.

O subperíodo semeadura-emergência durou, em média, seis dias (Figura 1) para as datas de semeadura entre $4 / 2$ e $17 / 6$. Observou-se que nas semeaduras de março e início de abril a duração do subperíodo ( 0 a 1$)$ foi de quatro a cinco dias, enquanto para o fim de abril até junho este valor aumentou para 7 a 8 dias. Esses valores foram similares aos obtidos por PINTO (1996), que em seu experimento realizado com zínia 'Double Choice Mixed', constatou 3,9 e 5,3 dias para as semeaduras realizadas, respectivamente, em fevereiro e abril.

Os subperíodos emergência - surgimento da primeira folha verdadeira (1 a 2) e da primeira folha verdadeira à segunda folha (2 a 3) duraram, em média, nas condições experimentais seis dias (Figura 1). Por sua vez PINTO (1996), para esses subperíodos, obteve valores de duração de 7,9 e 8,3 dias para as semeaduras de fevereiro e 10,4 e 10,0 dias para as semeaduras de abril.

Da segunda folha verdadeira até a visualização da gema apical (3 a 4), com pelo menos $2 \mathrm{~mm}$ de diâmetro, foram necessários em média 14 dias, enquanto para o subperíodo visualização da gema apical até o aparecimento da primeira flor aberta (4 a 5) a duração foi de 19 dias, variando entre extremos de 13 a 24 dias. Pinto (1996) relata que o subperíodo segunda folha verdadeira até o surgimento da gema apical visível durou 12,3 dias na semeadura de fevereiro e 16,9 dias para a semeadura de abril, nas condições de Jaboticabal (SP).

Considerando-se o subperíodo primeira flor aberta até $50 \%$ das flores abertas (5 a 6), observou-se que decorreram em média 11 dias, e para as semeaduras de abril a junho este valor aumentou para 12 a 16 dias. 


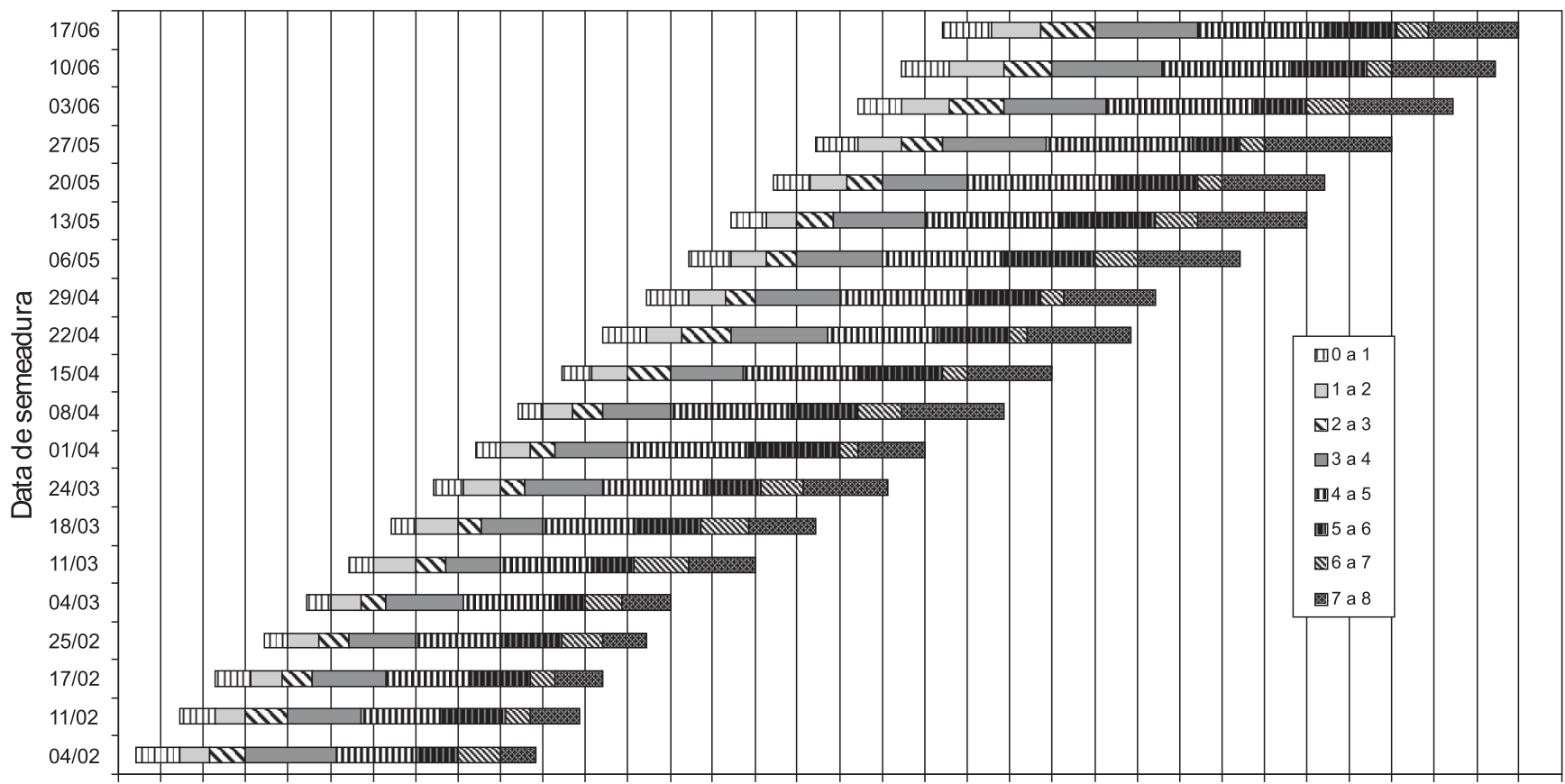

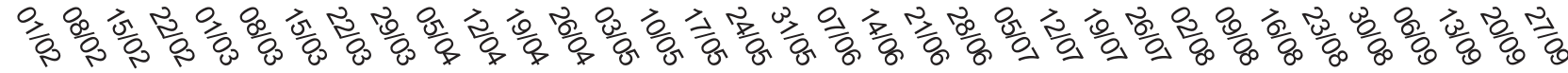

Data

Figura 1. Duração dos subperíodos fenológicos em dias, para zínia 'Profusion Cherry'envasada cultivada em ambiente protegido para diferentes datas de semeadura. Subperíodos: 0 a 1: semeadura a emergência; 1 a 2: emergência ao surgimento da primeira folha verdadeira; 2 a 3: surgimento da primeira folha verdadeira ao surgimento da segunda folha; 3 a 4: surgimento da segunda folha a visualização da gema apical (2 mm); 4 a 5: visualização da gema apical ao surgimento da primeira flor aberta; 5 a 6: surgimento da primeira flor aberta a 50\% das flores abertas; 6 a $7: 50 \%$ das flores abertas a 90\% das flores abertas; 7 a 8: 90\% das flores abertas a senescência; 0 a 8: semeadura à senescência.

Deste estádio fenológico até que fosse atingida a abertura de $90 \%$ das flores (6 a 7 ) decorreram apenas seis dias, em média.

As flores da zínia depois de totalmente abertas (estádio 7) até a senescência (estádio 8) duraram, nas condições de vaso e telado plástico, em torno de 14 dias, tendo sido observado que para as semeaduras efetuadas em fevereiro este valor foi de sete dias, enquanto para as outras datas de semeadura variou entre 14 e 18 dias.

A duração do ciclo total (0 a 8) da zínia, híbrido 'Profusion Cherry' foi em média de 80 dias. Observouse a tendência de encurtamento do ciclo (60-75 dias) nos tratamentos cuja semeadura ocorreu durante fevereiro e março, em comparação aos 91 a 98 dias necessários para a planta completar seu ciclo nos tratamentos com semeaduras efetuadas em maio e junho.

Do ponto de vista prático os subperíodos considerados mais importantes seriam: a) subperíodo 0 a 5: semeadura - abertura da primeira flor, ou seja, o momento em que o produtor teria as plantas aptas para serem comercializadas no mercado varejista; $b$ ) subperíodo 5 a 6: primeira flor, até $50 \%$ das flores abertas, representando o período máximo que o varejista teria para vender as flores envasadas ao consumidor; c) subperíodo 6 a 8: $50 \%$ das flores abertas até a senescência, ou seja, o período de duração das flores para o consumidor final.

No subperíodo 0 a 5 , relativo ao tempo em que a planta fica com o produtor, verificou-se que sua duração variou entre 39 e 63 dias. Na tabela 1, são apresentados os valores médios da duração deste subperíodo fenológico para as diferentes datas de semeadura, além do resultado da comparação feita por análise de intervalo de confiança. Verificou-se que os menores valores da duração do subperíodo 0 a 5 (39 dias) ocorreram para as semeaduras efetuadas entre o fim de fevereiro e a primeira quinzena de março. Os maiores valores da duração do subperíodo (60 a 63 dias) foram observados nas semeaduras de junho.

Em relação ao comércio varejista, representado pelo subperíodo 5 a 6 , ou seja, correspondente à duração do período em que as flores teriam melhores condições de venda ao consumidor, variou entre 7 e 
16 dias para as diferentes épocas de semeadura analisadas. Observou-se grande variabilidade na duração do subperíodo 5 a 6 para as diferentes épocas de semeadura, provavelmente em razão da diminuição da temperatura do ar de fevereiro a junho e do sistema de avaliação que compreendia leituras em períodos de três a quatro dias, e pode ter influído na determinação da duração desse subperíodo, que foi curto.

Tabela 1. Duração média do subperíodo fenológico semeadura - primeira flor aberta (0 a 5), em dias, e resultado da comparação de intervalos de confiança para zínia 'Profusion Cherry', envasada, cultivada em ambiente protegido para diferentes datas de semeadura. Monte Alegre do Sul (SP), 2005

\begin{tabular}{lccc}
\hline $\begin{array}{l}\text { Data de } \\
\text { semeadura }\end{array}$ & $\begin{array}{c}\text { Duração } \\
(0 \mathrm{a} \mathrm{5})\end{array}$ & $\begin{array}{c}\text { Data de } \\
\text { semeadura }\end{array}$ & $\begin{array}{c}\text { Duração } \\
(0 \mathrm{a} \mathrm{5})\end{array}$ \\
\hline $4 / 2$ & dias & & dias \\
$11 / 2$ & $44,7 \mathrm{~b}$ & $15 / 4$ & $46,8 \mathrm{~b}$ \\
$17 / 2$ & $42,8 \mathrm{~b}$ & $22 / 4$ & $52,3 \mathrm{c}$ \\
$25 / 2$ & $40,6 \mathrm{~b}$ & $29 / 4$ & $50,3 \mathrm{c}$ \\
$4 / 3$ & $39,6 \mathrm{ab}$ & $6 / 5$ & $51,1 \mathrm{c}$ \\
$11 / 3$ & $42,0 \mathrm{ab}$ & $13 / 5$ & $52,9 \mathrm{~cd}$ \\
$18 / 3$ & $39,4 \mathrm{a}$ & $20 / 5$ & $54,6 \mathrm{~d}$ \\
$24 / 3$ & $39,4 \mathrm{a}$ & $27 / 5$ & $57,4 \mathrm{~d}$ \\
$1 . .^{\circ} 4$ & $40,4 \mathrm{~b}$ & $3 / 6$ & $60,1 \mathrm{e}$ \\
$8 / 4$ & $42,4 \mathrm{~b}$ & $10 / 6$ & $62,9 \mathrm{e}$ \\
\hline
\end{tabular}

Médias seguidas de mesma letra não diferem entre si, ao nível de $5 \%$, por análise de intervalos de confiança.

No caso da duração do subperíodo 6 a 8 , representativo do tempo em que o consumidor teria as flores de zínia com bom aspecto, verificou-se que foi em torno de 12 a 25 dias, sendo as durações mais longas ( 20 a 25 dias) para os meses de temperaturas mais baixas (maio e junho).

\section{Efeito da temperatura e do fotoperíodo na duração do ciclo}

As estimativas de duração de ciclo foram feitas para o subperíodo (0-5): semeadura-primeira flor aberta, pois este é o de maior interesse para o produtor, uma vez que na fase fenológica em que a primeira flor encontra-se aberta, determina-se o ponto de entrega da flor para comercialização.

Observou-se variação da duração do subperíodo semeadura-primeira flor aberta, em relação à temperatura do ar e ao fotoperíodo, em função da data de semeadura.

A comparação entre o inverso da duração do subperíodo: 0-5 (semeadura-primeira flor aberta) e a temperatura média do ar, permitiu obter a seguinte equação de regressão simples:

$$
1 / \mathrm{D}=-0,00505 \mathrm{~T}+0,001232\left(\mathrm{R}^{2}=0,86\right)
$$

sendo $\mathrm{D}$ a duração do subperíodo considerado em dias, $\mathrm{T}$ a temperatura média do ar em ${ }^{\circ} \mathrm{C}$.

O coeficiente de determinação da equação de regressão obtida explicou $86 \%$ da variação da duração do subperíodo em função da temperatura. Observouse, também, que houve efeito da temperatura no sentido de diminuir a duração do subperíodo ou aumentar a taxa de desenvolvimento.

Ao ser considerado o efeito aditivo (BERTERo et al., 1999 e RoDrigues et al., 2001) da temperatura e do fotoperíodo, a equação obtida para estimativa da taxa de desenvolvimento no subperíodo semeaduraprimeira flor aberta foi:

$$
1 / \mathrm{D}=0,0191+0,0019 \mathrm{~T}-0,0035 \mathrm{~F} \quad\left(\mathrm{R}^{2}=0,99\right)
$$

sendo $\mathrm{D}$ a duração do subperíodo considerado em dias, $\mathrm{T}$ a temperatura média do ar em ${ }^{\circ} \mathrm{C}, \mathrm{F}$ o fotoperíodo médio no subperíodo, em horas.

O valor do coeficiente de determinação foi $\mathrm{R}^{2}$ $=0,99$ demonstrando que a utilização da temperatura do ar e do fotoperíodo de maneira conjunta permite estimativas mais aprimoradas de duração do subperíodo 0-5, do que quando se considerou apenas a temperatura do ar e foi obtido valor de $\mathrm{R}^{2}$ de 0,86 .

A comparação entre os valores (duração do subperíodo: semeadura - primeira flor aberta) observados e estimados em função da temperatura e do fotoperíodo foi feita, em conjunto independente de dados e está apresentada na figura 2.

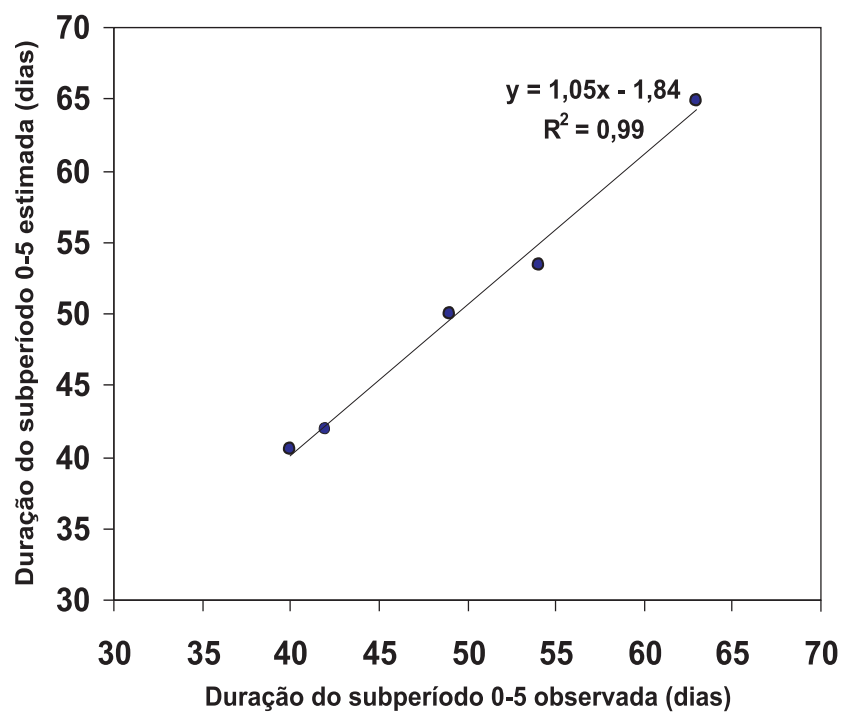

Figura 2. Comparação entre valores observados e estimados da duração do subperíodo: 0-5 (semeaduraprimeira flor aberta) para zínia 'Profusion Cherry' envasada cultivada em ambiente protegido. Monte Alegre do Sul (SP), 2005. 
A equação de regressão obtida apresentou coeficiente linear de 1,84 e o coeficiente angular, muito próximo da unidade, ou seja, 1,05, revelando que as estimativas do conjunto independente de dados em função da temperatura e do fotoperíodo foram consistentes.

O teste para validação da estimativa da duração do subperíodo 0-5 apresentou coeficiente de correlação $R^{2}=0,99$ e o índice de concordância de Willmott $\mathrm{d}=0,999$, mostrando que as estimativas, em função da temperatura e do fotoperíodo podem ser feitas com boa precisão e exatidão, com erro médio absoluto de apenas 0,2 dias.

\section{CONCLUSÕES}

1. A duração do subperíodo 0 a 5 , que variou entre 39 e 63 dias, teve influência da temperatura e do fotoperíodo. Valores decrescentes de temperatura aumentaram a duração do subperíodo;

2. A duração do subperíodo 0 a 5 pode ser estimada em função da temperatura e do fotoperíodo.

\section{REFERÊNCIAS}

BASS, L.N. Flower seed storage. Seed Science and Technology, Zurich, v.8, p.591-599, 1980.

BERTERO, H.D.; KING, R.W.; HALL, A.J. Modelling photoperiod and temperature responses of flowering in quinoa (Chinopodium quinoa Willd.). Field Crops Research, n.63, p.1934, 1999.
GONÇALVES, C. Fenologia, exigências bioclimáticas e características físicas da zínia 'Profusion cherry' envasada cultivada em ambiente protegido. 2006. 54p. Dissertação (Mestrado) - Instituto Agronômico, Campinas.

GONZÁLES, M.I.; POZO, A. del; COTRONEO, D.; PERTIERRA, R. Dias de floración en espinaca (Spinacia oleracea L.) en diversas épocas de siembra: respuesta a la temperatura y al fotoperíodo. Agricultura Técnica, v.64, n.4 p. 331-337, 2004.

PINTO, A.C.R. Efeito de época de semeadura e de sistemas de condução sobre a fenologia, o crescimento e a produção de inflorescências de Zinnia elegans Jacq. 1996. 137f. Dissertação (Mestrado) - Faculdade de Ciências Agrárias e Veterinárias UNESP, Jaboticabal.

RODRIGUES, O.; DIDONET, A.D.; LHAMBY, J.C.B.; BERTAGNOLLI, P.F. LUZ, J.S. Resposta quantitativa do florescimento da soja à temperatura e ao fotoperíodo, Pesquisa Agropecuária Brasileira, Brasília, v.36, n.3, p.431-437, 2001.

SACALIS, J. N. Cut flowers prolonging freshness. 2.ed. Batavia: Ball, 1993. 110 p.

TORRES, A.M. Taxonomy of Zinnia. Brittonia, New York, v.15, p.1-25, 1963.

VIEIRA, S. Introdução à bioestatística. Rio de janeiro, Elsevier, 1980. 196p.

WILLMOTT, C. J.; ACKLESON, S. G.; DAVIS, R. E.; FEDDEMA, J. J.; KLINK, K. M.; LEGATES, D. R.; O’DONNEL, J.; ROWE, C. M. Statistics for the evaluation and comparison of models. Journal of Geophysical Research, Washington, D.C., n.90 (c5), p.8995-9005, 1985.

YAN, W. \& WALLACE, D.H. Simulation and predict of plant phenology for five crops bases on photoperiod $x$ temperature interaction. Annals of Botany Company, Oxford, n.81, p.705716, 1998. 